\title{
RELAÇÕES REFERENCIAIS EM FRASES COORDENADAS E SUBORDINADAS ADVERBIAIS
}

\author{
Nádia Canceiro ${ }^{11}$
}

\section{RESUMO}

O objetivo deste estudo é analisar as relações referenciais que se estabelecem entre sujeitos em frases coordenadas e subordinadas adverbiais (integradas e não integradas). A observação do comportamento destes elementos irá fornecer pistas em relação às propriedades dos sujeitos omitidos e realizados nestas construções e às configurações estruturais que lhe estão subjacentes. Para complementar a abordagem teórica, construiu-se uma Tarefa de Juízo de Referência,de forma a obter todas as interpretações associadas a cada frase. Este estudo permitiu-nos perceber que a barreira entre coordenação e subordinação adverbial vai para além daquilo que está descrito.

Palavras-chave: coordenação, subordinação adverbial, relações referenciais, estruturas sintáticas.

\begin{abstract}
This study aims at analyzing the referential relations established between subjects in coordinate and adverbial (integrated and non-integrated) clauses. The observation of the behavior of these elements will provide clues regarding the properties of the omitted and overt subjects in these constructions and the syntactic structures of these sentences. To complement the theoretical approach, we built a Reference Judgment Task, to obtain all of the interpretations associated to each sentence. This study allowed us to understand the barrier betweten coordination and adverbial subordination goes beyond what is traditionally proposed.
\end{abstract}

11 Faculdade de Letras da Universidade de Lisboa. E-mail: nadia.canceiro@campus.ul.pt 
Keywords: coordination, adverbial subordination, referential relations, syntactic structures.

\section{Introdução}

O presente trabalho tem por base a abordagem da gramática generativa atual (Teoria de Princípios e Parâmetros, Chomsky 1981; e Programa Minimalista, Chomsky 1995 e seguintes) e pretende contribuir para a compreensão de aspetos relacionados com as propriedades dos sujeitos omitidos e realizados em construções de coordenação e subordinação adverbial, e também para a definição das configurações associadas a estas frases.

As frases coordenadas têm sido analisadas por autores como Munn (1993), Johannessen (1998), Kayne (1994), Matos (1995, 2005, 2009), Colaço (1998, 2005), Matos \& Raposo (2013), entre outros. A par, as construções subordinadas adverbiais foram também alvo de estudos por Chomsky (1981, 1986), Haegeman (1991), Kayne (1994), Cinque (1999), Ernst (2000, 2002), Lobo (2003), Valmala (2009). Porém, nenhum destes trabalhos se debruçou, de forma sistemática, sobre as relações referenciais que se estabelecem entre sujeitos e sobre as pistas que essas relações nos fornecem em termos estruturais. Além disso, os trabalhos referidos não são consistentes nas suas abordagens, uma vez que, dependendo das análises, frases coordenadas e subordinadas são analisadas com configurações de Especificador-Núcleo-Complemento e de Adjunção.

Assim, com este trabalho, e recorrendo a uma tarefa de cariz experimental de forma a validar os dados, pretendemos contribuir para a caracterização dos sujeitos omitidos, para a definição da configuração sintática das frases em estudo e para a compreensão da adequação das propostas estruturais.

\section{Coordenação vs. Subordinação Adverbial}

\subsection{Diferenças e semelhanças}

Os aspetos que aproximam e separam coordenação e subordinação adverbial foram alvo de trabalhos por autores como Quirk et al (1985), Haspelmath (2004), Matos (2003, 2006) e Lobo (2003). Porém, a distinção entre estas duas construções nem sempre é fácil, uma vez que o seu comportamento sintático é semelhante por "constituírem proposições fechadas ou totais, não funcionando como argumento nuclear integrado noutra proposição nem como modificador de um argumento nuclear" (Lobo 2003: 18). 
Alguns autores referem como característica distintiva o facto de a oração coordenada não desempenhar nenhuma função sintática ou semântica na coordenante, sendo que, em relação à subordinação adverbial, o mesmo parece não acontecer, embora, de acordo com Lobo, a função que a adverbial desempenha na subordinante não seja clara.

Existem vários argumentos para aproximar e separar coordenação de subordinação, porém consideramos que apenas dois, apresentados em Matos (2003), permitem distinguir claramente coordenação de subordinação:

(i) a sensibilidade dos conectores (conjunções coordenativas vs. complementadores) à natureza finita ou infinitiva da frase que encabeçam, uma vez que as frases coordenadas não exibem esta sensibilidade;

(1) a. Ele disse que queria ter boa nota e que estudou para isso.

b. Ele disse querer ter boa nota e ter estudado para isso.

(2) a. Ele disse que queria ter boa nota porque estudou para isso.

b. *Ele disse querer ter boa nota porque ter estudado para isso.

c. Ele disse querer ter boa nota por ter estudado para isso.

(ii) o facto de as frases coordenadas poderem ser formadas a partir da coordenação de constituintes de várias categorias sintáticas, ao passo que as frases subordinadas adverbiais são sempre compostas por elementos frásicos.

(3) a. A Joana e o João comeram um bolo. (coordenação de DPs)

b. A Maria entregou os livros ao Pedro e ao João. (coordenação de PPs)

c. A Ana leu um livro recente e muito interessante. (coordenação de APs)

Canceiro (2016: 26) 
Em relação a outras propriedades tipicamente consideradas distintivas, assumimos que a possibilidade de alterar a ordem pela qual os termos ocorrem é apenas particularmente aceite:

(4) a. O Pedro come uma fatia de bolo e o João come uma tarte.

b. *O João come uma tarte (,) o Pedro come uma fatia de bolo e.

c. *E o João come uma tarte (,) o Pedro come uma fatia de bolo.

(5) a. O João ficou em casa porque está doente.

b. Porque está doente, o João ficou em casa.

(6) a. A Maria lê tantos romances como o João policiais.

b. *Como o João policiais (,) a Maria lê tantos romances.

Canceiro (2016: 23)

Quanto à extração de constituintes, esta só é possível em coordenação quando ocorre de forma simultânea (Across-the-board Movement, ATB, Ross 1967), isto é, quando um constituinte é extraído de cada termo coordenado. Em frases subordinadas, a omissão de constituintes ocorre recorrendo à estratégia de lacunas parasitas (Parasitic Gaps, Engdahl 1983), em que um constituinte é omitido na oração adjunta, sendo legitimado por um vestígio de movimento A' na frase matriz. Tendo em conta que as estratégias de omissão de constituintes em coordenação e subordinação (ATB movement e Parasitic Gaps) apresentam algumas semelhanças, consideramos que não constituem um argumento suficientemente forte para distinguir as duas construções.

Em relação à possibilidade de articular mais do que dois constituintes, Lobo (2003), Matos (1995) e Colaço (2005) referem que tal só é possível em frases coordenadas, com exceção das adversativas, vejam-se os exemplos abaixo:

(7) a. Fui à livraria, (e) $)^{12}$ fui ao cinema e fui ao café.

b. Ficaste em casa, (ou) foste ao cinema, ou foste ao café?

12 Tipicamente as conjunções encontram-se omitidas e só a última é realizada. 
c. *Não fiquei em casa, (mas) fui ao cinema, mas fui ao café.

Quanto ao padrão de colocação de clíticos, parece-nos que, embora seja comummente referido como distintivo entre coordenação e subordinação, com os dados apresentados em Martins (2013) e Matos e Colaço (2014), a sua validade como factor de diferenciação pode ser questionada.

Nestes trabalhos, Martins (2013), e Matos e Colaço (2014), mostram que, diferentemente do que é tradicionalmente proposto, sob determinadas condições estruturais, pode ocorrer próclise em frases coordenadas, tal como se verifica nos exemplos abaixo:

(8) a. Das duas uma: ou as faz ela ou as faço eu.

b. */?? Das duas uma: as fá-las ela ou faço-as eu.

Matos e Colaço (2014: 7)

Assim, tendo em conta os argumentos apresentados, consideramos que existem apenas dois factores verdadeiramente distintivos: (i) a sensibilidade dos conectores à natureza finita ou infinitiva das frases, e (ii) o facto de apenas as frases coordenadas poderem ser formadas a partir de constituintes de várias categorias sintáticas.

\subsection{Aspetos estruturais da coordenação e da subordinação}

As estruturas de coordenação e subordinação foram já alvo de várias análises e apresentam, dependendo da análise, diferentes configurações estruturais. As frases coordenadas podem, por isso, ser analisadas numa configuração de Especificador-Núcleo-Complemento (Kayne 1994; Matos 1995, 2003; Johannessen 1998; Colaço 1998, 2005) ou de Adjunção (Munn 1993). Em relação à subordinação, as mesmas configurações foram adotadas: Adjunção (Chomsky 1981; Haegeman 1991; Ernst 2002; Lobo 2003) e Especificador-Núcleo-Complemento (Kayne 1994; Cinque 1999).

\subsubsection{A estrutura da coordenação}

Os estudos feitos para a coordenação estabelecem que existe uma relação mais próxima entre a conjunção coordenativa e o termo que, em línguas como o português, ocorre à sua direita. Por 
este motivo, e também porque a projeção do núcleo da conjunção coordenativa é obrigatoriamente preenchida, a conjunção é o núcleo destas frases. Assim, trabalhos como os de Munn (1993), Johannessen (1998), Kayne (1994), Matos (1994, 2000), e.o., assumem que na configuração estrutural da coordenação, a conjunção é o núcleo de uma projeção própria construída em termos da Teoria X-barra.

No entanto, o tratamento da estrutura sintática não é consensual e, por isso, coexistem as propostas de Adjunção e Especificador-Núcleo-Complemento.

A proposta de Adjunção de Munn (1993) tem como característica principal a existência de um operador Booleano (B) que tem a capacidade de unir categorias. Segundo esta proposta, o primeiro termo da frase coordenada não se encontra em posição de especificador de BP, e a projeção BP (conjunção) adjunge-se à direita do primeiro termo coordenado, que é designado por Munn como XP.

(9) Estrutura de Adjunção para a coordenação

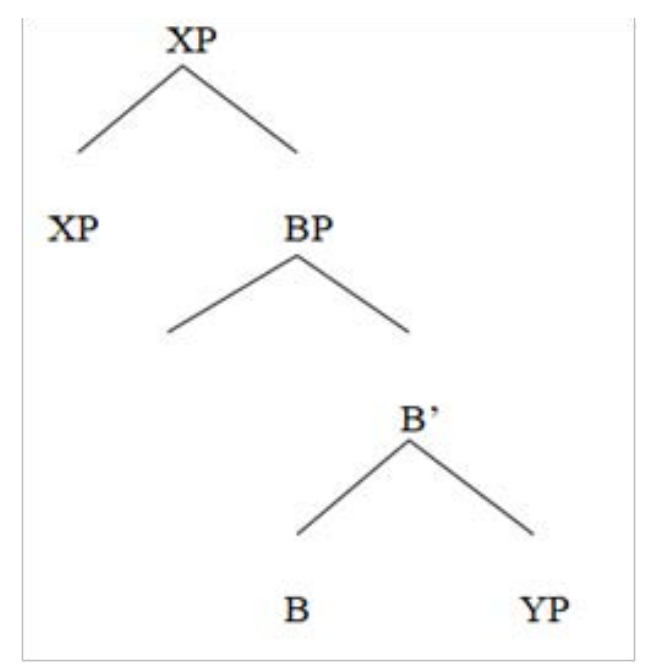

Munn refere ainda que esta proposta apresenta vantagens em questões de ligação de constituintes, na análise de estruturas com extração Across-the-board, e na coordenação de constituintes assimétricos. Porém, trabalhos como Matos (2005) referem que esta proposta não consegue dar conta de casos de concordância plena de sujeitos coordenados com o verbo flexionado, nem de construções que envolvem extração ATB, uma vez que Munn afirma que existe uma posição de especificador no ConjP que é ocupada por um operador nulo, e, na verdade, essa posição nunca pode ser preenchida por gerar frases agramaticais. 
Como alternativa, temos a hipótese de projeção em Especificador-Núcleo-Complemento, em que o primeiro termo coordenado ocupa a posição de especificador, não ocorrendo, por isso, fora da projeção da estrutura coordenada, como acontece na proposta de Munn.

(10) Estrutura de Especificador-Núcleo-Complemento para a coordenação

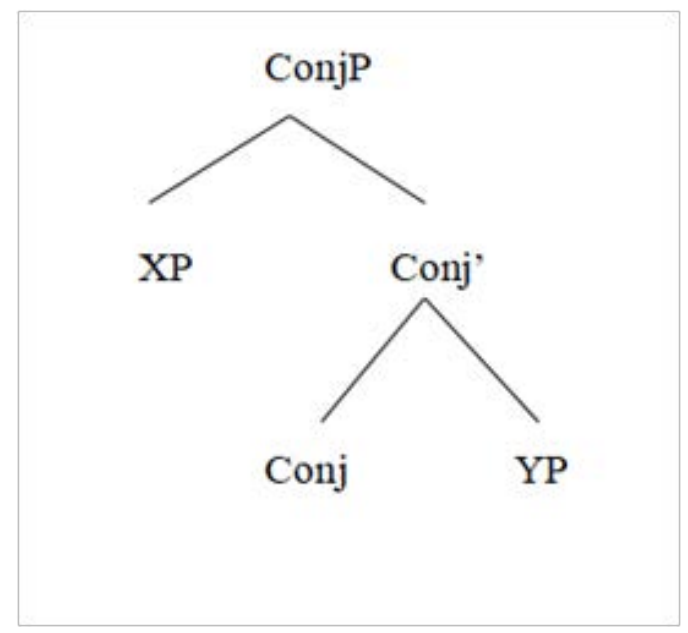

Ao adotar esta configuração, assume-se que as frases coordenadas integradas são derivadas por Merge, mais especificamente Set-Merge. Esta análise foi adotada por vários autores para a coordenação integrada, parcialmente por Johannessen (1998) e sistematicamente por Matos (1995, 2003), Colaço (1998, 2005), entre outros. Trabalhos como os de Zhang (2010) mostram que apenas uma estrutura binária pode dar conta das assimetrias que se verificam na ligação de constituintes e do facto de a conjunção apresentar sempre um maior grau de proximidade com um dos termos coordenados.

Matos (1997, 2000, 2009) e Colaço (1998) referem que Conj assume por Agree os traços do seu especificador. Assim, através da concordância especificador-núcleo, o especificador fornece os seus traços ao núcleo e, por isso, ConjP será categorialmente idêntico ao primeiro termo coordenado. Desta forma é também possível dar conta da relação de c-comando do primeiro termo sobre o segundo. Em casos de coordenação oracional é particularmente relevante a relação de c-comando que se verifica entre os dois termos.

Embora se considere que tanto a estrutura de Adjunção, como a de Especificador-NúcleoComplemento podem permitir a coordenação de constituintes de categorias sintáticas diferentes e permitem captar a preponderância do primeiro termo face ao segundo, assumimos que, para o PE, 
apenas a de Especificador-Núcleo-Complemento permite dar conta do facto de ambos os termos serem selecionados pela conjunção e de a coordenação de duas expressões nominais singulares dar origem a uma expressão nominal plural.

\subsubsection{A estrutura da subordinação adverbial}

As frases subordinadas adverbiais correspondem a um processo de articulação de frases por hipotaxe e funcionam como modificadores adverbiais em relação à frase matriz. As orações adverbiais não são selecionadas pelo predicador como argumentos, manifestando, por isso, opcionalidade e apresentando um menor grau de coesão, quando comparadas com as completivas, em relação à frase matriz.

Porém, as orações adverbiais podem apresentar diferentes graus de coesão em relação à frase matriz. Assim, dividir-se-ão entre orações adverbiais integradas, quando o grau de coesão é forte, e, não integradas, quando, pelo contrário, o grau é menor e as adverbiais se encontram menos integradas na matriz. Em Lobo (2003) são apresentados vários testes que permitem distinguir frases adverbiais integradas de não integradas. As orações que podem ocorrer nos contextos apresentados nos testes, sem se tornarem agramaticais, serão consideradas integradas, diferentemente das não integradas que, nestes contextos, se tornam agramaticais. As orações não integradas podem ainda diferir quanto à sua posição, uma vez que podem ocorrer à direita ou à esquerda da frase matriz (Lobo 2003).

Tal como acontece com as frases coordenadas, também em relação às propostas de análise das frases subordinadas adverbiais não há consenso. Com efeito, também as orações adverbiais foram analisadas quer em termos de Especificador-Núcleo-Complemento (Larson 1988, 1990; Kayne 1994; e.o.), quer em termos de Adjunção (cf. Chomsky 1981, 1986, 2004, 2008; Haegeman 1991; Barbiers 1995; Ernst 2002; Lobo 2003).

A proposta de Especificador-Núcleo-Complemento de Kayne e Cinque, tal como apresentada em Lobo (2003), surge como uma alternativa à estrutura de Adjunção à direita: 


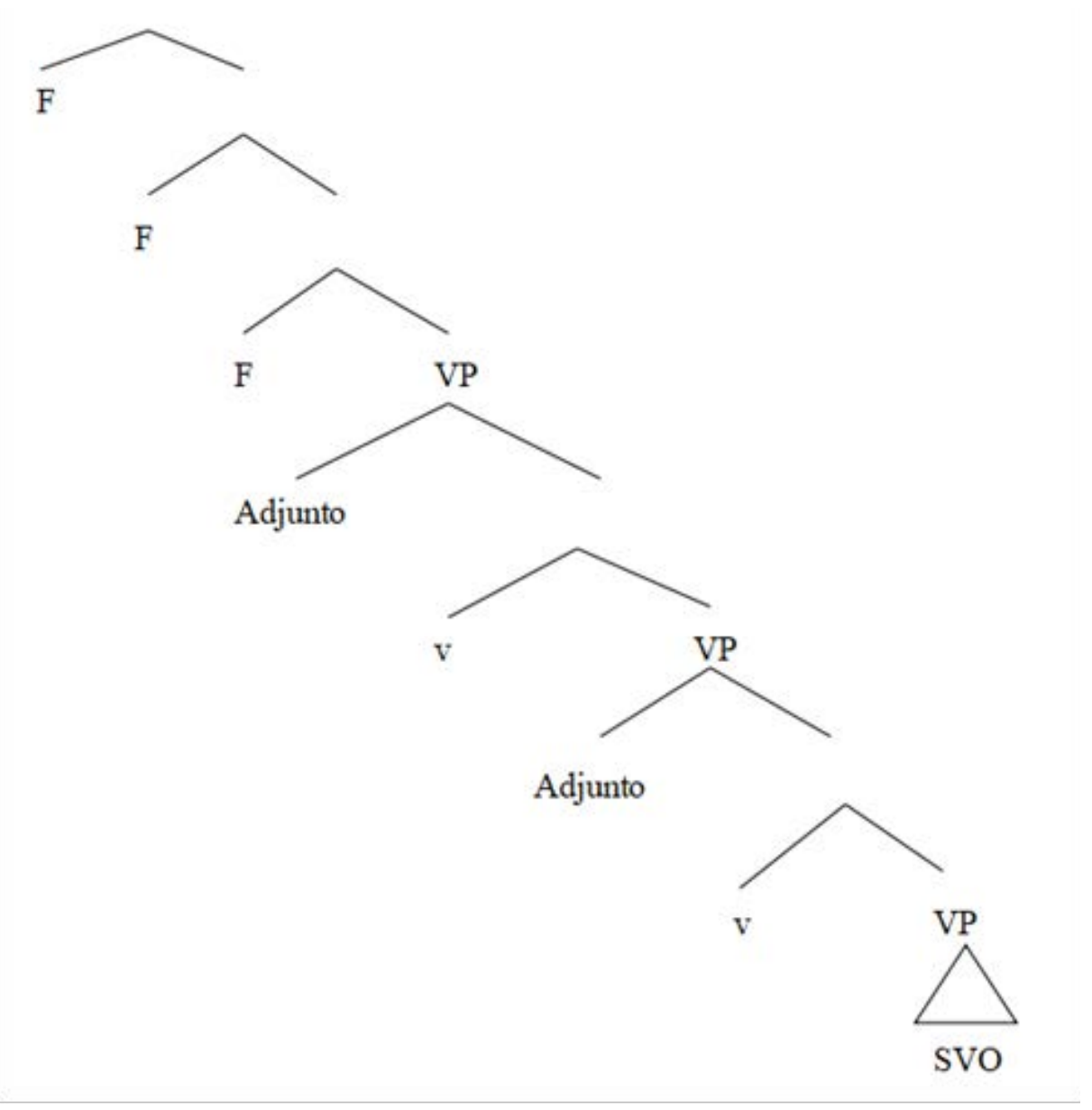

Esta proposta decorre da análise de Cinque para os advérbios, que considera a existência de várias projeções funcionais (cerca de 40) que codificam vários subtipos de modo, modalidade, tempo, aspeto e força ilocutória. Nesta análise assume-se que os modificadores adverbiais de VP são gerados basicamente à esquerda de VP e, posteriormente, são movidos sucessivamente de forma a derivar a posição final do adjunto. Autores como Lobo (2003) e Kiss (2009) objetam esta análise por considerarem que implica assumir a existência de vários núcleos verbais vazios para os quais não há evidência empírica. Lobo (2003) refere ainda que esta configuração é problemática por não dar conta da correlação entre o parâmetro OV/VO e a posição dos adjuntos, nem da obrigatoriedade/não obrigatoriedade de movimento em certos casos.

A estrutura de Adjunção é defendida por vários autores (Williams 1994a, 1994b; Ernst 2000, 2002; e.o.) que reconhecem que esta configuração apresenta alguns problemas, nomeadamente o requisito de antissimetria, contudo consideram que é menos problemática do que a de Especificador- 
Núcleo-Complemento (veja-se (15)).

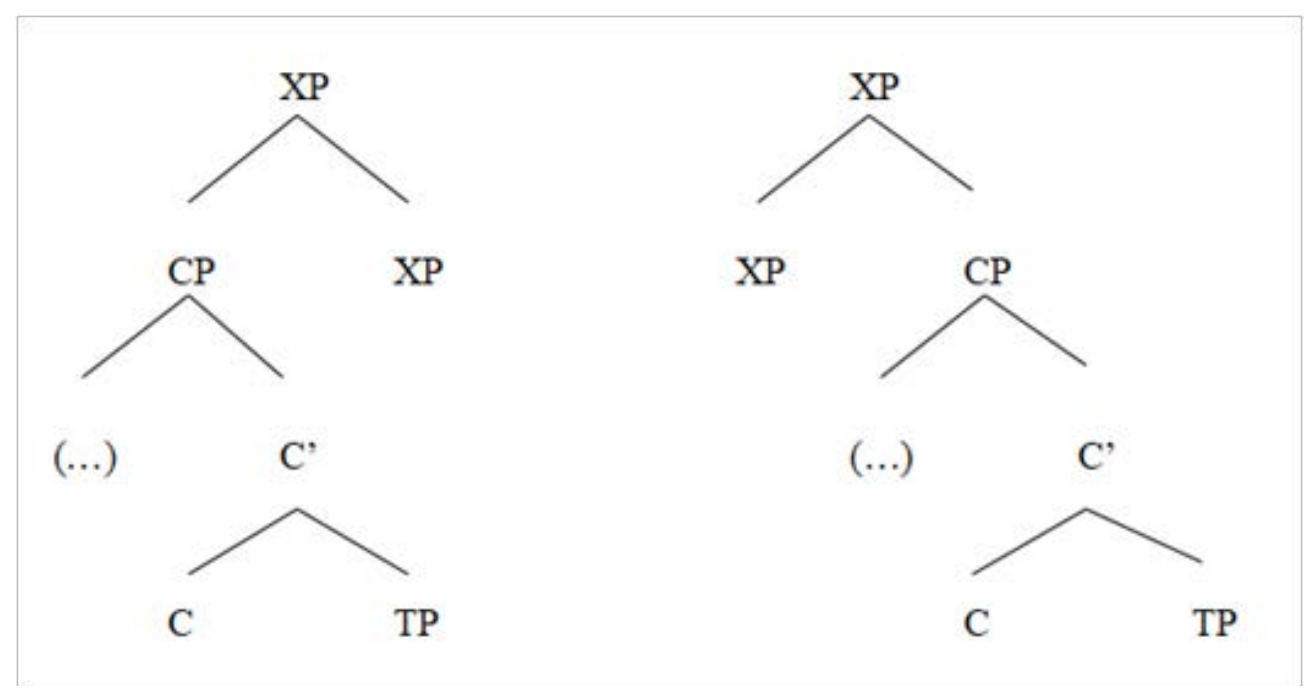

A Adjunção de adverbiais pode ocorrer à esquerda ou à direita, como se observa em (15), desde que cumpra requisitos semânticos que possibilitem a sua interpretação. Na representação apresentada acima, XP pode assumir vários valores (CP, TP, VP), dependendo do nível em que ocorre a adjunção. Assim, orações que ocorrem em adjunção a VP estarão mais integradas na matriz do que aquelas que ocorrem adjuntas a TP ou CP.

Esta proposta foi também alvo de objeções, principalmente pelo facto de ser pouco restritiva e, por isso, poder sobre-gerar (overgenerate) e criar estruturas agramaticais. Contudo, assume-se que esta questão pode ser solucionada tendo em conta, por exemplo, factores prosódicos (efeitos de peso).

Assim, seguindo a proposta de Lobo (2003) para o PE, considera-se que a proposta de Adjunção é a mais adequada para este trabalho, visto que apresenta menos problemas, e mais facilmente solucionáveis, do que a configuração de Especificador-Núcleo-Complemento.

\section{Comportamento referencial de sujeitos}

Nesta secção apresentar-se-ão as propostas da literatura que analisam o comportamento referencial dos sujeitos em frases coordenadas e subordinadas adverbiais. Assumimos que o 
comportamento dos sujeitos, realizados e omitidos, nestas frases nos fornecem informação relevante para a definição das configurações estruturais e do conteúdo referencial dos sujeitos.

\subsection{A Teoria da Ligação}

De forma a dar conta das relações referenciais que se estabelecem entre constituintes nominais, Chomsky propõe a existência de três princípios que captam o comportamento de anáforas, pronominais e expressões referenciais:

(16) Binding Theory

(A) An anaphor is bound in its governing category.

(B) A pronominal is free in its governing category.

(C) An R-expression is free.

Chomsky (1981: 188)

Assim, constituintes que não têm capacidade de referência (anáforas) devem ser ligados:

(17) A Maria ${ }_{i}$ levanta-se $e_{i}$ muito cedo.

Os pronominais são constituintes que podem ter referência dependente ou independente e dividem-se entre os que são foneticamente realizados e os que não o são:

(18) a. A Maria estuda língua portuguesa quando ela ouve música.

b. A Maria estuda língua portuguesa quando [-] ouve música.

Chomsky refere ainda que os pronominais podem ter uma leitura de disjunção (18a), quando o pronome é realizado, ou de correferência, quando o pronome é omitido (18b).

Em relação ao princípio $\mathrm{C}$, as expressões- $\mathrm{R}$ são aquelas que apresentam maior autonomia referencial, são sempre constituídas por elementos nominais e devem ser sempre livres (i.e., não 
ligadas).

A Maria ${ }_{\mathrm{i}}$ diz que a Maria $_{*_{\mathrm{i} j}}$ só ouve música portuguesa.

Para este trabalho, de forma a dar conta das relações que se estabelecem nos domínios coordenados e adverbiais, recorreremos aos princípios apresentados.

\subsection{Sujeitos em frases coordenadas}

Em frases complexas coordenadas, entre os constituintes em posição de sujeito, estabelecem-se relações de correferência ou disjunção. Apresentam-se abaixo as definições de Chomsky (1995: 154155) para estes conceitos:

(20) Se o índice de $\alpha$ é idêntico ao índice de $\beta$, então $\alpha$ e $\beta$ são co-referentes.

(21) Se o índice de $\alpha$ é distinto do índice de $\beta$, então $\alpha$ e $\beta$ são referencialmente disjuntos.

Embora a ocorrência de pro em frases coordenadas finitas, na posição de sujeito do segundo termo coordenado, seja legítima, considera-se que, em PE, a estratégia de movimento Across-theboard (ATB) é preferencial.

A estratégia de ATB surge como uma forma de escapar à Condição da Estrutura Coordenada (Ross 1967), que não permite a extração de constituintes de uma frase coordenada. Porém, Ross mostra que se a extração afetar constituintes de ambos os termos coordenados é possível obter uma frase gramatical.

Colaço (2005) refere também que a estratégia de extração ATB permite evitar, de acordo com princípios de economia da gramática, a repetição de material redundante, que, por vezes, pode afetar a interpretação da frase:

(22) A Maria foi à livraria e a Maria comprou dois livros.

Colaço (2005: 289)

O facto de o constituinte [A Maria] surgir em ambos os termos da frase coordenada pode afetar 
a interpretação se se pretender induzir correferência. Porém, em (23), onde o constituinte [A Maria] não surge no segundo termo da coordenação, a única interpretação possível é de correferência.

(23)A Maria foi à livraria e [-] comprou dois livros.

Embora esta estratégia seja comummente aceite, há várias análises em relação ao local para onde e de onde se dá o movimento de constituintes. Alguns autores consideram que o movimento se dá para o exterior da estrutura coordenada e de duas posições para apenas uma. Outros, diferentemente, apresentam a possibilidade de o movimento de constituintes ocorrer no interior dos termos coordenados. Porém, independentemente deste aspeto, considera-se que, nas frases em que há movimento ATB, a interpretação do constituinte omitido é de partilha dos traços referenciais, uma vez que o movimento deixa uma cópia.

\subsection{Sujeitos em frases subordinadas adverbiais}

De acordo com a Teoria da Ligação, os sujeitos omitidos em frases subordinadas adverbiais finitas, e com infinitivo flexionado, são pronominais e, por isso, obedecem ao Princípio B. Desta forma podem originar leituras de correferência ou de disjunção face ao seu antecedente e, desde que o Princípio B seja respeitado, o antecedente pode, ou não, c-comandar o pronominal ((24) e (25)).

(24) Embora $[-]^{13}$ esteja triste, o João ${ }^{13}$ vai à festa.

(25) Embora o Joãoi esteja triste, $[-]^{13}$ vai à festa.

Existem ainda alguns autores que consideram que a Teoria de Controlo (Chomsky 1981) se pode aplicar a construções finitas, ou com infinitivo flexionado, porém assumimos que, nas frases analisadas, o que ocorre é diferente do Controlo tal como descrito em Chomsky (1981), Hornstein (1999) e Landau (2000). Neste trabalho, consideraremos que o que ocorre na posição de sujeito é um pronominal, sendo que, quando não é realizado, corresponde a pro.

\section{Tarefa experimental}

Considerando o que foi apresentado nas secções anteriores, verifica-se que não há consenso

13 Tipicamente as conjunções encontram-se omitidas e só a última é realizada. 
nos estudos relacionados com coordenação e subordinação, nem nos aspetos que as aproximam e separam. Assim, considerámos importante testar o comportamento dos falantes relativamente às relações referenciais que se estabelecem entre sujeitos nestas frases.

As tarefas realizadas incidiram sobre o sujeito do segundo termo da frase coordenada e da oração adverbial. Nas frases testadas na primeira tarefa, o sujeito do segundo termo coordenado e da oração adverbial estava omitido, na segunda tarefa o sujeito do primeiro termo coordenado, ou da frase matriz, era realizado como um pronome, e o sujeito do segundo termo coordenado, ou da oração adverbial, era realizado sob a forma de uma expressão-R. O objetivo da primeira tarefa era aferir se, nestas construções, a relação que se estabelece é obrigatoriamente de correferência, a partir do momento em que há partilha de referência em termos dos valores dos traços- $\phi$. Considerou-se que os resultados obtidos não permitiam, de forma suficientemente esclarecedora, alcançar os objetivos deste trabalho, por isso, criou-se uma nova tarefa com sujeitos realizados, de forma a melhor compreender o comportamento referencial dos sujeitos nestas frases.

\subsection{Questões de investigação e hipóteses}

Tendo em conta as características das construções coordenadas e subordinadas adverbiais, assim como das análises que dão conta das propriedades dos sujeitos omitidos nestas frases, interessa perceber se, por exemplo, as fronteiras estabelecidas entre coordenação e subordinação adverbial são robustas ou, se, pelo contrário, existem aspetos que esbatem esta fronteira. Assim, colocamos as seguintes questões de investigação:

(i) Os diferentes tipos de coordenação (aditiva, adversativa, disjuntiva) apresentam, realmente, as mesmas propriedades estruturais?

(ii) Existe uma diferença clara, em termos estruturais, entre subordinação adverbial integrada e subordinação adverbial não integrada?

(iii) Nas construções com subordinação adverbial não integrada, a posição da subordinada adverbial relativamente à frase matriz tem efeitos relevantes sobre a estrutura?

(iv) Deverá a diferença entre coordenação e subordinação adverbial ser pensada em termos estruturais? Se sim, que aspetos estruturais diferenciam as frases coordenadas das frases subordinadas 
adverbiais?

Pensamos que, respondendo a estas perguntas, conseguiremos contribuir para a compreensão das características destas frases e do comportamento dos sujeitos, e para a definição das suas configurações estruturais. Tendo em conta estas questões, apresentam-se, de seguida, as hipóteses de trabalho.

Hipótese 1: Há uma clara distinção estrutural entre coordenação e subordinação adverbial. Entre si, os diferentes tipos de frases coordenadas e os diferentes tipos de subordinadas adverbiais têm propriedades estruturais idênticas. Esta hipótese, conduz a um tratamento semelhante ao que é tradicionalmente proposto, separando coordenação de subordinação adverbial.

Hipótese 2: As frases coordenadas e as subordinadas adverbiais têm todas elas estruturas semelhantes. Esta hipótese remete a distinção entre coordenação e subordinação para fatores não estruturais.

Hipótese 3: Não existe uma distinção estrutural clara entre as frases coordenadas e as frases com subordinação adverbial, dado que nem umas nem outras apresentam propriedades estruturais homogéneas. De acordo com esta hipótese, a distinção a fazer poderá passar mais por aspetos como o maior ou menor grau de integração das frases envolvidas, ou o valor semântico dos conectores que unem as frases, do que propriamente pela distinção clássica entre coordenação e subordinação.

Assim, a partir destas hipóteses, criou-se uma tarefa experimental de forma a testar, de uma forma sistemática, as relações estruturais que se estabelecem no interior de cada domínio sintático. A observação destas relações permitirá aferir quais as propriedades de cada estrutura em análise e dos constituintes em posição de sujeito.

\subsection{Metodologia}

Para este trabalho, de forma a poder responder às questões de investigação apresentadas anteriormente, criámos uma tarefa experimental baseada na Tarefa de Juízo de Referência (Reference Judgment Task) de McDaniel e Cairns (1990a, 1990b).

McDaniel e Cairns descrevem a Tarefa de Juízo de Referência (TJR) para estudos em que 
o objetivo é aceder à gramática dos falantes de modo a obter informação sobre a referência que se estabelece numa determinada frase. Embora esta tarefa esteja descrita para estudos associados à aquisição da linguagem, pode ser também aplicada com vantagem a falantes adultos.

A TJR foi escolhida para este trabalho por permitir, não só obter a interpretação preferencial associada a cada frase, mas também por permitir saber se existe mais do que uma interpretação possível. Esta tarefa deu origem a dois testes: o primeiro com sujeitos omitidos no segundo termo coordenado ou na oração adverbial; e o segundo com sujeitos realizados (pronominais e expressões-R). Em ambos, a tarefa consiste numa série de frases, apresentadas sem contexto, seguidas de uma pergunta sobre o conteúdo das mesmas, e três opções de resposta. Vejam-se os seguintes exemplos:

(26) Ele deu aulas e [-] estudou Biologia.

Quem deu aulas?

a. A mesma pessoa que estudou Biologia (interpretação de sujeitos correferentes)

b. Outra pessoa (interpretação de sujeitos disjuntos)

c. As respostas a. e b. são ambas possíveis (interpretação de sujeitos correferentes / disjuntos)

(27) A Rita podia comer um bolo porque [-] foi à padaria.

Quem foi à padaria?

a. A Rita (interpretação de sujeitos correferentes)

b. Outra pessoa (interpretação de sujeitos disjuntos)

c. As respostas a. e b. são ambas possíveis (interpretação de sujeitos correferentes / disjuntos)

(28) Ele deu aulas e o João estudou Biologia. 
Quem deu aulas?

a. A mesma pessoa que estudou Biologia (interpretação de sujeitos correferentes)

b. Outra pessoa (interpretação de sujeitos disjuntos)

c. As respostas a. e b. são ambas possíveis (interpretação de sujeitos correferentes / disjuntos)

(29) Ela podia comer um bolo porque a Rita foi à padaria.

Quem podia comer um bolo?

a. A mesma pessoa que foi à padaria (interpretação de sujeitos correferentes)

b. Outra pessoa (interpretação de sujeitos disjuntos)

c. As respostas a. e b. são ambas possíveis (interpretação de sujeitos correferentes / disjuntos)

Na TRJ optámos por não fornecer qualquer contexto, uma vez que se considerou que tal poderia desambiguar de alguma forma a interpretação das frases quanto à relação que se estabelece entre os sujeitos. Para que em todas as frases existisse a possibilidade de correferência, as frases foram, em todos os casos, construídas de forma a que se verificasse uma coincidência em termos dos valores dos traços- $\phi$ (pessoa, número, género) entre os referidos sujeitos. Embora esta coincidência possa, em alguns casos, ter levado a interpretações preferenciais de correferência, a sua ausência iria induzir interpretações obrigatoriamente disjuntas, o que tornaria o teste ineficaz.

\subsubsection{Teste 1}

O primeiro teste, baseado na TJR, é constituído por 56 itens aleatorizados: 42 frases-teste (cada condição foi testada três vezes) e 14 frases distratoras (que correspondem a um terço das frases-teste). O teste foi realizado sem tempo limite, num modelo off-line em suporte papel. Apresentam-se abaixo 
dois exemplos de frases testadas:

(30) Ele deu aulas e estudou Biologia.

Quem estudou Biologia?

a. A mesma pessoa que deu aulas

b. Outra pessoa

c. As respostas a. e b. são ambas possíveis

(31) A Diana podia comer um bolo porque foi à padaria.

Quem foi à padaria?

a. A mesma pessoa que podia comer um bolo

b. Outra pessoa

c. As respostas a. e b. são ambas possíveis

As frases (30) e (31) mostram que, na primeira tarefa, foram testadas frases em que o primeiro sujeito é realizado como um pronome ou uma expressão-R, respetivamente, e o segundo é foneticamente nulo.

Participaram nesta tarefa 20 sujeitos (12 do sexo feminino e 8 do sexo masculino), com uma média de 24,6 anos. Todos os informantes são licenciados e 5 concluíram também o mestrado, contudo nenhum tem formação teórica em Linguística. Nenhum informante foi informado previamente sobre o objetivo do teste e todos são falantes de Português Europeu.

\subsubsection{Teste 2}

De forma a comprovar as relações que o teste 1 sugere, construiu-se uma segunda tarefa em que, diferentemente da primeira tarefa, o sujeito no segundo termo coordenado, ou na oração adverbial, se 
encontra realizado.

Inicialmente, realizou-se o teste com todas as condições em apenas uma sessão, sem limite de tempo, mas com o objetivo de que o terminassem em menos de 40 minutos. Posteriormente, de forma a excluir a interferência de fatores como o cansaço, que poderia afetar os juízos dos falantes, e também o facto de alguns informantes terem realizado o teste no tempo que se considerou máximo, repetiu-se o teste, dividindo-o em duas sessões ${ }^{14}$.

Assim, na primeira experiência participaram 40 informantes (27 do sexo feminino; 13 do sexo feminino), estudantes de licenciatura da Faculdade de Letras da Universidade de Lisboa (FLUL), com uma média de 19,8 anos de idade. Nenhum dos informantes teve conhecimento do objetivo da experiência, não possuíam formação teória em linguística e eram todos falantes de PE.

Na segunda experiência participaram 33 informantes (30 do sexo feminino; 3 do sexo masculino), estudantes de licenciatura da FLUL, com uma média de 19,7 anos de idade. Todos cumprem os mesmos requisitos da primeira experiência.

No segundo teste consideraram-se frases coordenadas e subordinadas adverbiais em que o sujeito do primeiro termo, ou da frase matriz, é realizado sob a forma de um pronome e o do segundo termo coordenado, ou da oração adverbial, é uma expressão-R.

A condição testada definiu-se como (32):

(32) Pronome Lexical_Conjunção/Complementador_Expressão Referencial

Saliente-se que a formulação da condição não corresponde a uma ordenação linear, mas sim a uma dependência hierárquica. Este aspeto é particularmente relevante para as orações adverbiais não integradas à esquerda, em que o complementador e o sujeito da adverbial ocorrem à esquerda do sujeito da frase matriz.

Os resultados obtidos com esta condição são de particular relevância para a definição de aspetos estruturais de frases coordenadas e subordinadas adverbiais. A possibilidade de correferência nestas construções é fulcral: se a correferência for possível, a expressão-R que instancia o segundo sujeito 14 Note-se que o teste foi dividido em duas sessões devido à sua extensão. Neste trabalho apenas se apresentam os resultados de uma das condições testadas. 
apenas respeitará o princípio C da Teoria da Ligação se não for c-comandada pelo primeiro sujeito, isto é, pelo pronome; inversamente, se a disjunção for possível, assumiremos que se deve a efeitos do princípio $\mathrm{C}$, concluindo, assim, que na estrutura em causa, a expressão-R é ligada pelo pronome, ou seja, o primeiro sujeito c-comanda o segundo.

Apresentam-se abaixo exemplos de frases testadas:

(33) Ele aprendeu viola na escola e o João estudou Francês num centro de línguas.

(34) Ela aprendeu Inglês mas a Maria tirou um curso de Geologia.

(35) Ela estudou para teste ou a Ana foi ter com as amigas.

(36) Ele jantou às 23.00 porque o Simão saiu tarde do trabalho.

(37) Ele ficou zangado, embora o João tenha pedido desculpa.

(38) Uma vez que o ele gosta de doces, o Luís trouxe das Caldas.

Esta tarefa é composta por 54 itens: 18 frases-teste, 22 frases distratoras e 14 itens de controlo. Todas as frases foram aleatorizadas e foram criadas 4 versões do teste. Este teste foi também apresentado num modelo off-line, em suporte papel e em ambiente de sala de aula. Optou-se por não limitar o tempo, nem o contabilizar de outra forma, uma vez que se considera que a velocidade de resposta não era um factor relevante para este trabalho.

As respostas dos informantes foram, posteriormente, anotadas numa folha Excel e procedeu-se à sua análise. A transcrição dos dados foi feita com base em dois parâmetros: acerto (distratores e itens de controlo foram classificados como certo ou errado ${ }^{15}$ ) e tipo de resposta (para as frases-teste considerou-se que em todas era possível obter leituras de correferência, disjunção e correferêncial disjunção).

Apresentam-se, de seguida, os resultados obtidos em ambos os testes, em frases coordenadas e subordinadas adverbiais.

\section{Resultados}

Nas subsecções seguintes apresentam-se e discutem-se os resultados das tarefas experimentais

15 Consideraram-se para análise os dados referentes aos informantes que acertaram em $50 \%$ ou mais das respostas a este tipo de frase. 
realizadas. Inicialmente serão apresentados os resultados da primeira tarefa, de forma a aferir se em construções em que o sujeito do segundo termo coordenado ou da oração adverbial é nulo, a interpretação é obrigatoriamente de correferência. De seguida apresentam-se os resultados do teste 2 (com ambos os sujeitos realizados) para que se possam comprovar algumas das relações sugeridas pelos resultados do teste 1 .

\subsection{Coordenação}

O gráfico 1 mostra os juízos dos falantes em relação a frases coordenadas aditivas, adversativas e disjuntivas, em que o primeiro sujeito está realizado e o segundo é foneticamente nulo ( $\mathrm{SuN}$ ), tal como nos exemplos seguintes:

(39) Ele deu aulas e estudou Biologia.

(40) O João deu aulas e estudou Biologia.

(41) Ele estudou Linguística mas quer ser advogado.

(42) O Pedro estudou linguística mas quer ser advogado.

(43) Ela estudou para o teste ou foi ter com as amigas.

(44) A Sofia estudou para o teste ou foi ter com as amigas.

Gráfico 1 - Resultados teste 1: Estruturas Coordenadas

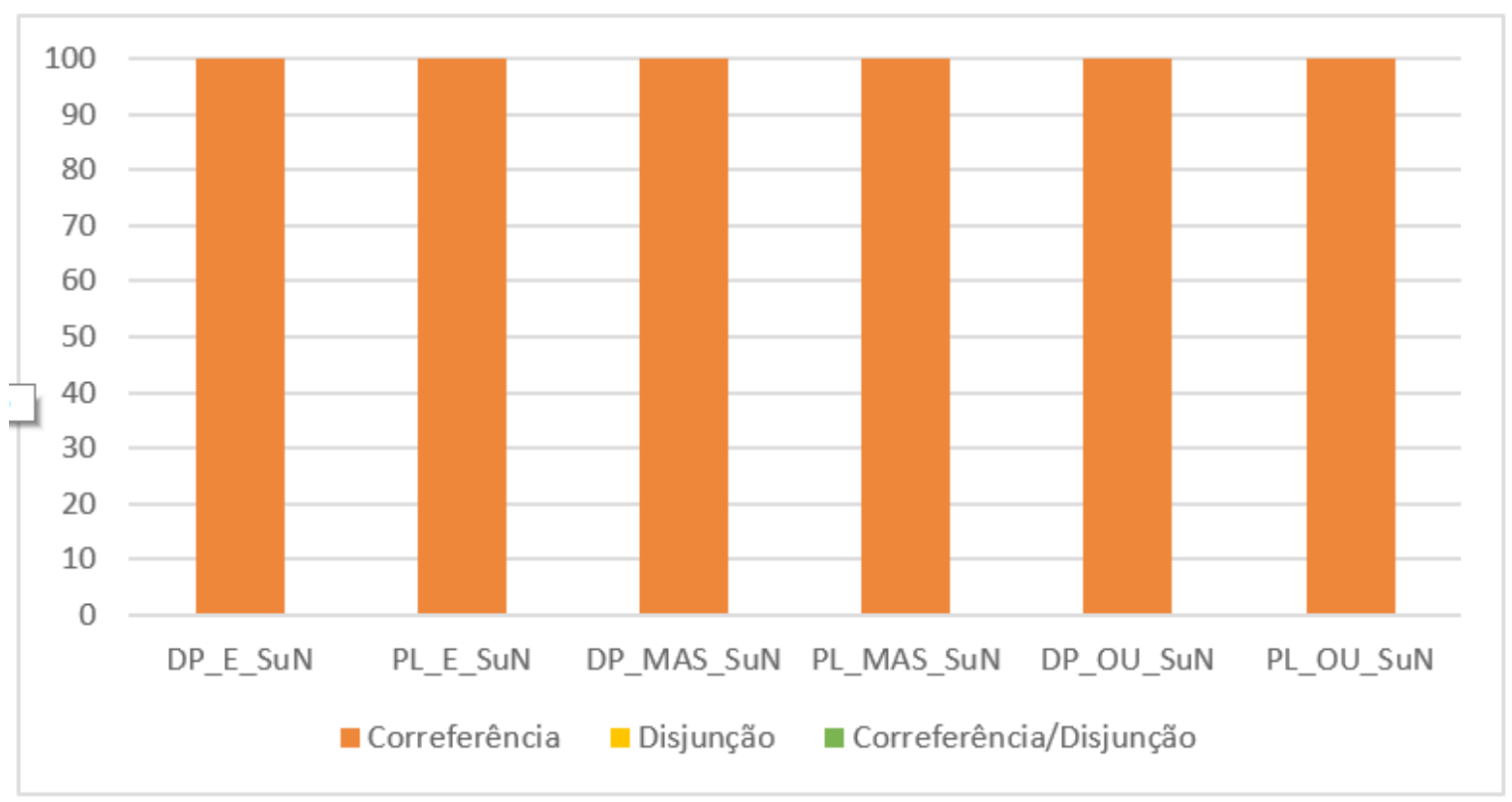


Os resultados obtidos, e apresentados no gráfico 1, mostram que, nestas construções (em que o segundo sujeito é foneticamente nulo), a interpretação de correferência não só é a preferida pelos informantes, como é a única possível, uma vez que em todas as condições os valores de preferência são de $100 \%$. Estes resultados sugerem a existência de uma relação de c-comando do primeiro sujeito sobre o segundo. Porém, esta relação terá de ser confirmada com os dados obtidos no teste 2, visto que correferência não implica, obrigatoriamente, c-comando. Apresentam-se abaixo os resultados obtidos no teste 2 e exemplos de frases testadas:

Gráfico 2 - Resultados teste 2: Estruturas Coordenadas

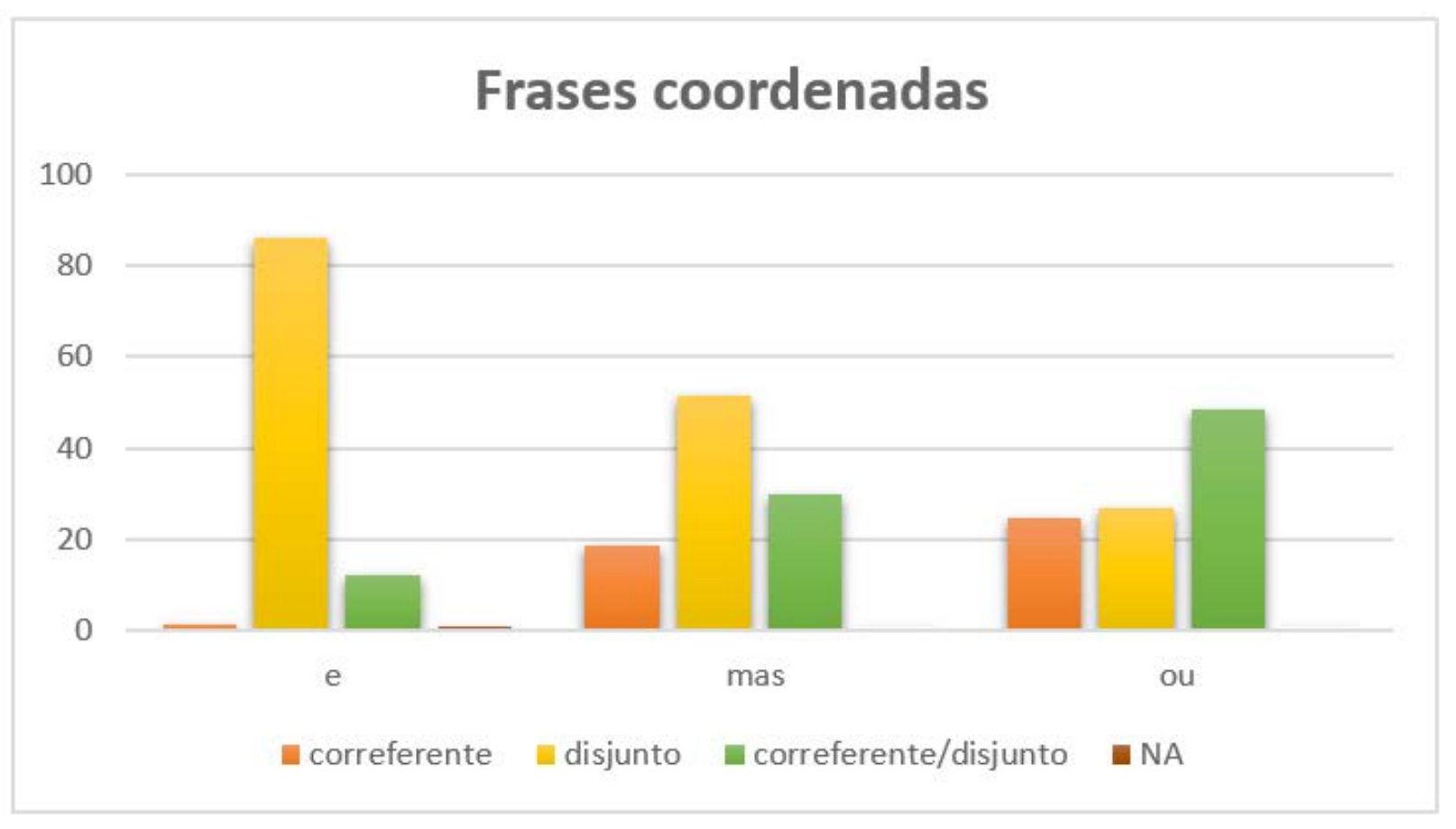

(45) Ele aprendeu viola na escola e o João estudou Francês num centro de línguas.

(46) Ela aprendeu Inglês mas a Maria tirou um curso de Geologia.

(47) Ela estudou para o teste ou a Ana foi ter com as amigas.

Os dados do gráfico 2 mostram que no caso das frases coordenadas aditivas há uma clara preferência por interpretações de disjunção, ou seja, em construções aditivas, em que o primeiro sujeito é um pronome e o segundo é uma expressão-R, os sujeitos não podem ser correferentes. Tal resultado, leva-nos a assumir que se verificam efeitos do princípio $\mathrm{C}$ da Teoria da Ligação, comprovando a relação de c-comando do primeiro sujeito sobre o segundo. 
Em relação às frases coordenadas adversativas, a leitura de disjunção também é a preferida, embora não de forma tão clara como no caso das aditivas. Por se verificar esta preferência, assumimos que também nas construções adversativas a relação de c-comando do primeiro sujeito sobre o segundo se estabelece, evidenciando efeitos do princípio $\mathrm{C}$.

Quanto às frases coordenadas disjuntivas, os resultados são surpreendentes, visto que tradicionalmente se assume que uma mesma configuração estrutural é atribuída a todos os tipos de frases coordenadas. Estes resultados mostram que os informantes aceitam simultaneamente a interpretação de correferência e de disjunção, que $27 \%$ aceita apenas a interpretação de disjunção e que $24,6 \%$ preferem a leitura de correferência.

Analisando os resultados obtidos, consideramos que nos fornecem informação relevante em relação às contrapartidas estruturais e ao conteúdo referencial dos sujeitos. Os dados do teste 1 demonstram que está subjacente a estas frases uma configuração de extração ATB (derivada através de sideward movement ${ }^{16}$, Nunes 1995, 2004), quando o sujeito do segundo termo está omitido. Assim, o constituinte que ocorre na posição do sujeito omitido irá corresponder a uma cópia-A (de movimento). No entanto, as cópias-A respeitam o princípio A, tal como as anáforas, e, tendo em conta que o domínio sintático das anáforas é menor, é necessário considerar duas hipóteses: (i) o domínio relevante é toda a frase coordenada, tal é possível porque se assume que todos os segmentos pertencem à mesma categoria; (ii) a estrutura coordenada por ser derivada (através de sideward movement) da forma proposta por Nunes $(1995,2004)$, tem a cópia mais alta projetada fora da estrutura coordenada e a c-comandar as duas cópias apagadas dos dois termos.

Em relação aos resultados obtidos para as frases coordenadas aditivas no teste 2, uma vez que a preferência por leituras de disjunção nos leva a assumir que existe uma relação de c-comando do sujeito do primeiro termo sobre o segundo, consideramos que este comportamento está conforme previsto na literatura para a coordenação integrada.

Quanto às construções coordenadas adversativas, tendo em conta que, na condição testada, a leitura preferencial também foi de correferência, considera-se que também se verificam efeitos so

16 A proposta de Sideward Movement (Nunes 1995, 2004) permite criar instâncias de movimento lateral que são obtidas através de apenas um item lexical que é copiado de um membro coordenado para o outro e, por fim, é copiado para o exterior da estrutura coordenada, de onde c-comanda as duas cópias apagadas. Note-se que, numa estrutura derivada através de sideward movement, os dois termos coordenados são derivados de forma independente. 
princípio C, ou seja, existe uma relação de c-comando do primeiro sujeito sobre o segundo. Contudo, em relação aos resultados obtidos para as aditivas, nas adversativas verificou-se maior oscilação nas interpretações, colocamos como hipótese: (i) que além da interpretação integrada, os falantes admitem uma menos integrada, ou seja, a coordenação pode ocorrer noutro nível que não TP (CP, por exemplo); (ii) a existência de uma interpretação de coordenação não integrada parentética, em que o núcleo parentético cancela os efeitos de c-comando do sujeito do primeiro termo sobre o do segundo.

Os resultados obtidos para as coordenadas disjuntivas mostram um comportamento distinto em relação às restantes coordenadas. No caso das frases disjuntivas não se verifica uma tendência marcada para se verificarem efeitos do princípio $C$, consideramos duas hipóteses que podem justificar este comportamento: (i) a oração que funciona como segundo termo coordenado é interpretada como uma reformulação da predicação do primeiro termo, justificando-se assim um valor de ênfase/focalização; (ii) existem estruturas em que a coordenação é interpretada como não integrada, podendo existir um valor parentético, que, possivelmente, impede que se verifiquem efeitos de c-comando do primeiro termo sobre o segundo.

Assim, a ausência de homogeneidade de resultados no teste 2 mostra-nos que o conceito de coordenação deve ser reanalisado e que cada estrutura coordenada (aditiva, adversativa, disjuntiva) deve ser analisada autonomamente. Quanto à estrutura da coordenação, assumimos que a configuração Especificador-Núcleo-Complemento é adequada, mas deve ser tido em conta o facto de que a coordenação pode ocorrer em diversos níveis (VP, TP, CP, ...).

\subsection{Subordinação adverbial}

O gráfico 3 mostra os juízos dos falantes em relação a frases subordinadas adverbiais integradas, não integradas à direita e não integradas à esquerda, em que o primeiro sujeito está realizado e o segundo é foneticamente nulo ( $\mathrm{SuN})$, tal como nos exemplos seguintes:

(48) Ele jantou às 23.00 porque saiu tarde do trabalho.

(49) O João jantou às 23.00 porque saiu tarde do trabalho.

(50) Ela comprou um bolo, embora estivesse a fazer dieta. 
(51) A Violeta comprou um bolo, embora estivesse a fazer dieta.

(52) Uma vez que ela gosta de livros, comprou “Guerra e Paz”.

(53) Uma vez que a Mafalda gosta de livros, comprou "Guerra e Paz".

Gráfico 3 - Resultados teste 1: Estruturas Subordinadas Adverbiais

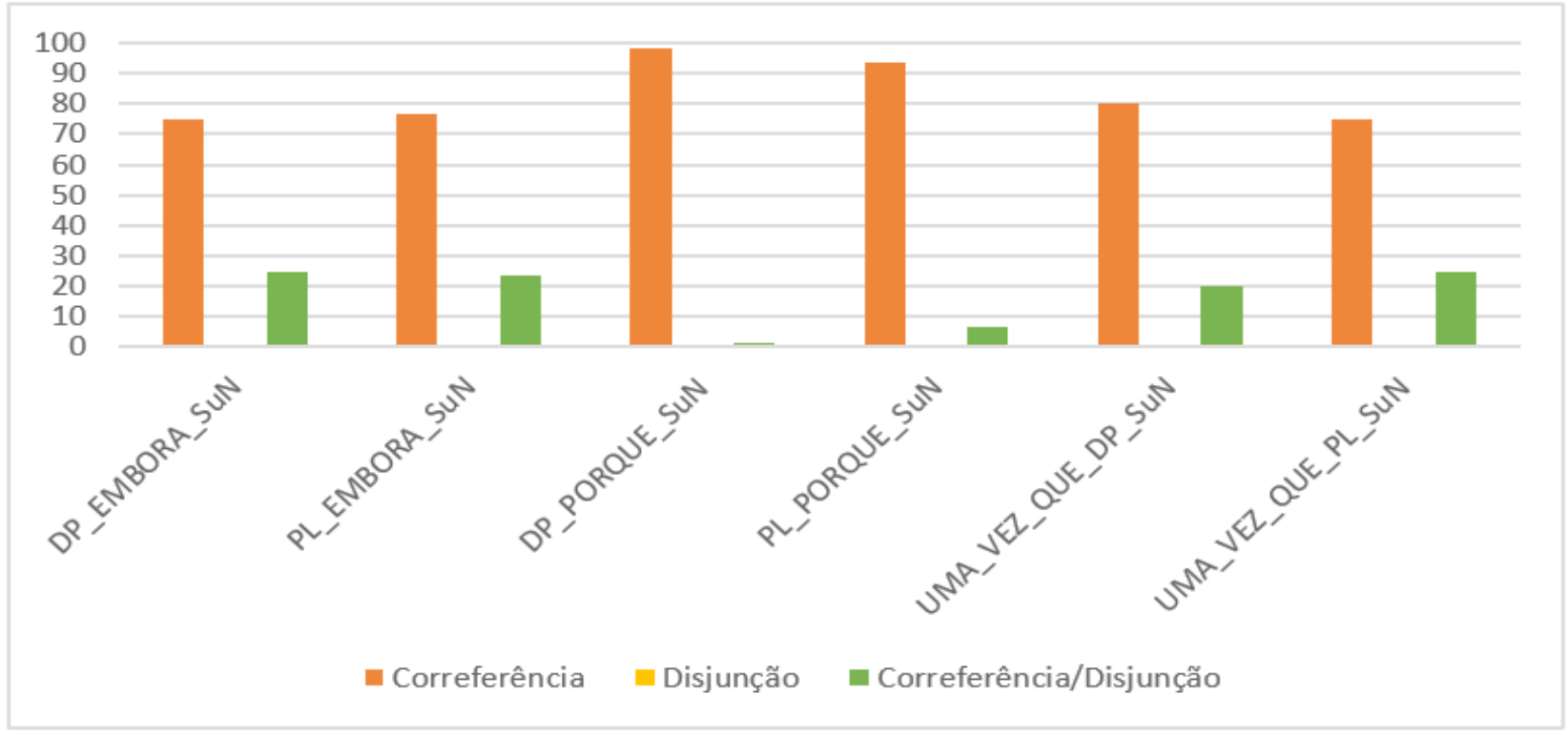

Através dos resultados obtidos é possível perceber que quando o sujeito da adverbial é nulo, a preferência é por interpretações de correferência. Porém, diferentemente do que acontece com as frases coordenadas, os juízos dos informantes não são unânimes. Embora estes resultados não sejam tão claros como no caso das coordenadas, o facto de o sujeito nulo permitir interpretações de correferência e disjunção, sugere que o constituinte nesta posição corresponde a um pro, uma vez que este pode alternar com o pronome lexicalmente realizado sem alterar a interpretação da frase.

Com efeito, no gráfico 2 é possível observar que a escolha de alguns informantes recai na possibilidade de obter uma interpretação de correferência/disjunção. Assim, e tendo em conta que estes dados não nos permitem afirmar com segurança as características dos constituintes omitidos nestas construções, apresentamos, de seguida, os resultados obtidos no teste 2 e exemplos de frases testadas. 
Gráfico 4 - Resultados teste 2: Estruturas Subordinadas Adverbiais

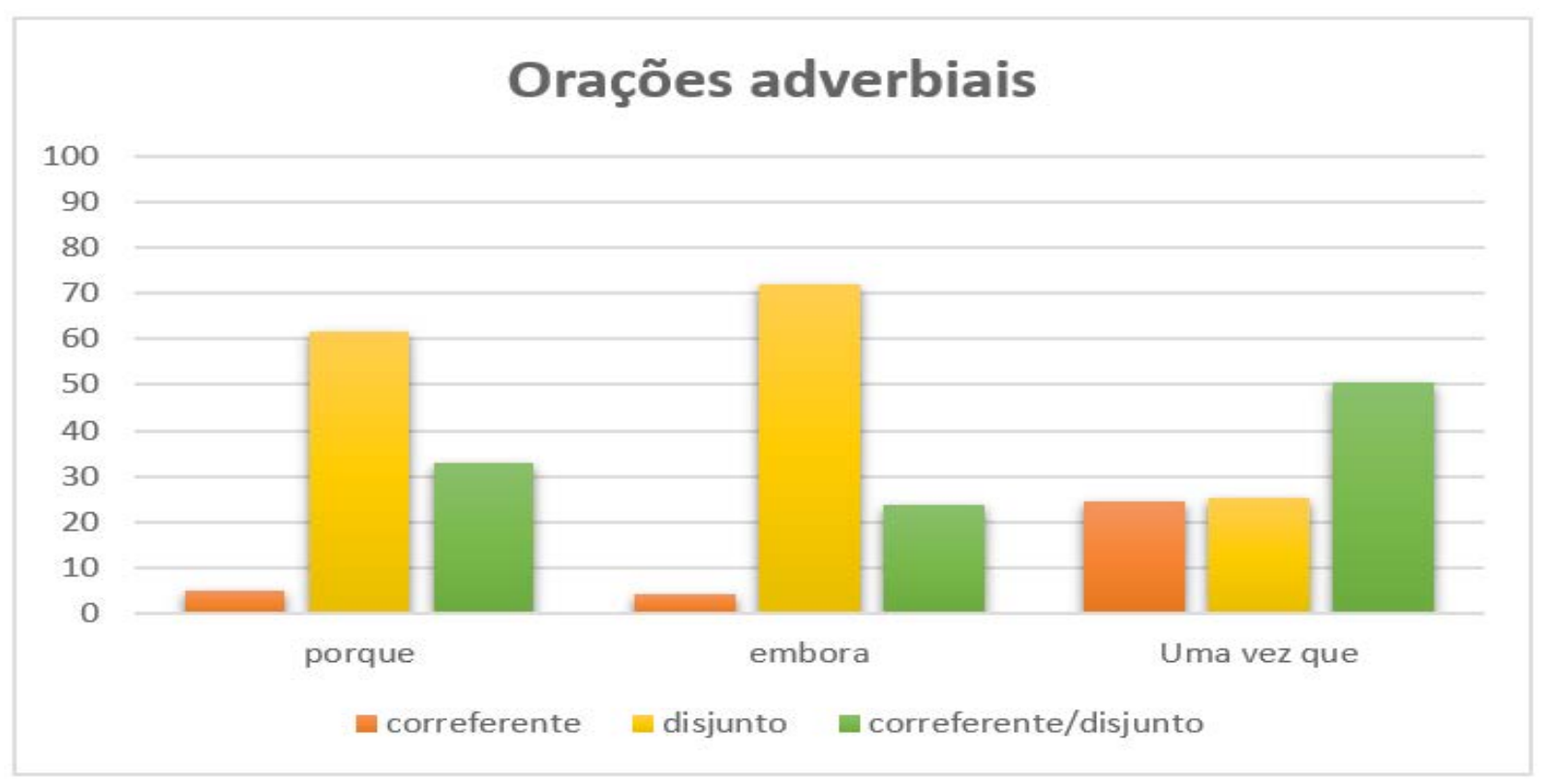

(48) Ele jantou às 23.00 porque o Simão saiu tarde do trabalho.

(49) Ele ficou zangado, embora o João tenha pedido desculpa.

(50) Uma vez que ele gosta de doces, o Luís trouxe das Caldas.

Os resultados obtidos no teste 2 mostram que nas orações integradas e nas não integradas à direita os informantes privilegiam interpretações disjuntas, o que sugere efeitos do princípio C e, por isso, uma relação de c-comando do sujeito da frase matriz sobre o da adverbial.

Em relação às orações não integradas à esquerda, os resultados mostram que não há preferência por interpretações de correferência ou de disjunção. $O$ facto de a correferência ser possível sugere que não há c-comando da adverbial sobre a matriz, tal como referido em Brito (2003) e Lobo (2003).

Analisando os resultados obtidos, em relação às orações integradas, verificamos que existe uma relação de c-comando, conforme descrito na literatura. Porém, existem também alguns informantes que aceitam a interpretação de correferência. Assumimos que esta possibilidade está associada ao facto de as orações com porque poderem pertencer ao grupo de orações integradas (causais) e não 
integradas (explicativas), e, por isso, permitirem, através da produção de uma pausa na leitura ${ }^{17}$, obter uma interpretação não integrada.

Em relação às adverbiais não integradas à direita, a preferência pela interpretação de disjunção mostra que, diferentemente do descrito na literatura, existe uma relação de c-comando do sujeito matriz sobre o da oração adverbial. Apesar de as orações com embora serem não integradas, não são parentéticas, porque, nesse caso, verificar-se-ia um bloqueio dos efeitos de c-comando.

As orações não integradas à esquerda apresentam resultados muito heterógeneos, que assumimos que se devem à ausência de c-comando, tal como referido em Brito (2003) e Lobo (2003). Lobo (2003) admite que estas estruturas são basicamente geradas numa posição alta, na periferia esquerda da frase matriz. Assumimos, neste trabalho, tal como Valmala (2009), que estas frases se podem aproximar dos casos de topicalização, tratados em Duarte (2003), em que a posição de especificador de TopP acolhe constituintes topicalizados basicamente gerados. Tendo em conta os resultados obtidos com a tarefa experimental, assumimos que a oração adverbial deve ser inserida diretamente na periferia esquerda, em especificador de TopP.

Assim, consideramos que a análise das construções adverbiais nos permitiu perceber que, além das orações integradas diferirem das não integradas, as não integradas também diferem entre si. Os resultados mostraram também bastante variação nos juízos dos informantes, o que, de certa forma, é esperado, uma vez que se tratam de estruturas não integradas e que, por isso, a articulação das orações pode ocorrer em diferentes níveis.

\section{Considerações finais}

Com este trabalho mostrou-se que, embora a coordenação e a subordinação adverbial apresentem diferenças e semelhanças, estas são diferentes das descritas na literatura. Os testes experimentais efetuados mostraram que o comportamento referencial das frases subordinadas adverbiais apresenta diferenças face ao descrito na literatura. Os dados obtidos permitiram perceber que, diferentemente do descrito, as frases adverbiais não integradas à direita apresentam efeitos de c-comando do sujeito matriz sobre o da adverbial. Relativamente às orações adverbiais integradas e não integradas à esquerda, o comportamento exibido pelos falantes na tarefa experimental permitiu corroborar a descrição encontrada na literatura relevante. A observação dos dados permitiu fornecer argumentos

17 Veja-se o conceito de Prosódia Implícita (Fodor 2002). 
adicionais que mostram que o sujeito omitido em construções adverbiais é um pro.

Em relação à coordenação, os dados mostram que, diferentemente do descrito, é necessário analisar cada tipo de frase coordenada (aditiva, adversativa ou disjuntiva) de forma autónoma, visto que, em termos referenciais, apresentam comportamentos distintos. Por este motivo, o conceito de coordenação terá de ser reanalisado à luz desta nova informação, ao invés de extrapolar as características da coordenação aditiva para as restantes construções coordenadas, como acontece frequentemente na literatura. De acordo com os resultados obtidos, assumimos que são possíveis interpretações de estruturas menos integradas ou parentéticas (com bloqueio de c-comando), e que o sujeito omitido é uma cópia-A.

Assim, confirmou-se a hipótese 3, uma vez que é a única que permite dar conta do comportamento referencial dos sujeitos nas construções analisadas, prevê a possibilidade de se comportarem de forma distinta e, por isso, corresponderem a representações estruturais diferentes.

Por fim, um dos objetivos deste trabalho era também perceber a adequação das configurações de Especificador-Núcleo-Complemento e de Adjunção. Tendo em conta os dados obtidos em termos de c-comando, assumimos que ambas são adequadas, no entanto, consideramos que em construções mais integradas, a configuração de Especificador-Núcleo-Complemento é mais vantajosa e que, pelo contrário, em frases com interpretações menos integradas, será a de Adjunção.

\section{REFERÊNCIAS}

BARBIERS, Sjef. The Syntax of Interpretation. Dissertação de doutoramento, Universidade de Leiden, 1995.

BRITO, Ana Maria. Subordinação Adverbial. In: MATEUS, M. H., et alii, Gramática da Língua Portuguesa. Lisboa: Caminho, 2003, p. 695-766.

CANCEIRO, Nádia. Coordenação, Subordinação Adverbial e Relações Referenciais entre Sujeitos. Dissertação de Mestrado, Faculdade de Letras da Universidade de Lisboa, 2016.

CINQUE, Guglielmo. Adverbs and Functional Heads. A Cross-Linguistic Perspective. New York/ Oxford: Oxford University Press, 1999. 
CHOMSKY, Noam. Lectures on Government and Binding. Dordrecht: Foris Publications, 1981. . Barriers. Cambridge, MA: The MIT Press, 1986.

. The Minimalist Program. Cambridge, MA: The MIT Press, 1995.

. Beyond explanatory adequacy. In: BELLETTI, Adriana (ed.). Structures and Beyond: The Cartography of Syntactic Structures, vol. 3. Oxford: Oxford University Press, 2004, p. 104-131. . The Essential Chomsky. Edited by Anthony Arnove. New York: The New Press, 2008.

COLAÇO, Madalena. Concordância parcial em estruturas de coordenação em Português Europeu. Actas do XIV Encontro Nacional da Associação Portuguesa de Linguística, vol. I. Lisboa: APL, 1998, p. 349-368.

. Configurações de Coordenação Aditiva: Tipologia, Concordância e Extracção. Dissertação de Doutoramento, Faculdade de Letras, Universidade de Lisboa, 2005.

DUARTE, Inês. Frases com tópicos marcados. In: MATEUS, M. H., et alli. Gramática da Língua Portuguesa. Lisboa: Caminho, 2003, p. 489-506.

ENGDAHL, Elisabet. Parasitic Gaps. Linguistics and Philosophy 6. Dordrecht, Holland, and Boston, USA: D. Reidel Publishing Co., 1983, p. 5-34.

ERNST, Thomas. On the Order of Event-Internal Adjuncts. In: Alexiadou, A.; Svenonius, P. (eds.). Linguistics in Potsdam, vol. 6. Postdam, Germany: University of Postdam, 2000, p. 33-49. . The Syntax of Adjuncts. Cambridge: Cambridge University Press, 2002.

FODOR, J. D. Psycholinguistics cannot escape prosody. In: Proceedings of the SPEECH PROSODY 2002 Conference. Aix-en-Provence, France: Laboratoire Parole et Langage : SProSIG, April 2002.

HAEGEMAN, Liliane. Introduction to Government and Binding Theory. Oxford: Blackwell, 1991. 
constructions. Amsterdam: Benjamins, 2004, p. 3-39.

HORNSTEIN, Norbert. Control as Movement. Linguistic Inquiry. v. 30, n. 1, p. 69-96, 1999.

JOHANESSEN, Janne Bondi. Coordinate-alpha and unbalanced coordination. In: KATHOL, A.; BERNSTEIN, M. (red.). ESCOL '93. Cornell: Cornell University, 1993, p. 153-62.

. Coordination. Oxford: Oxford University Press, 1998.

KAYNE, Richard. The Antisymmetry of Syntax. Cambridge MA: MIT Press, 1994.

KISS, Katalin É. Review of Principles of Syntactic Reconstruction, by Gisella Ferraresi \& Maria Goldbach (eds.). Diachronica, v. 26, n. 3, p. 448-455, 2009.

LANDAU, Idan. Elements of Control: Structure and Meaning in infinitival Contructions. Dordrecht ; Boston ; London: Kluwer Academic Publishers, 2000.

LARSON, Richard. On the Double Object Construction. Linguistic Inquiry, v. 19, n. 3, p. 335-391, 1988.

. Double Objects Revised: Reply to Jackendoff. Linguistic Inquiry, v. 21, n. 4, p. 589-632, 1990.

LOBO, Maria. Aspectos da Sintaxe das Orações Subordinadas Adverbiais do Português. Dissertação de Doutoramento, Faculdade de Ciências Sociais e Humanas, Universidade Nova de Lisboa, 2003.

MARTINS, Ana Maria. Posição dos pronomes pessoais clíticos. In: RAPOSO, Eduardo B. P.; NASCIMENTO, M Ma Fernanda B.; MOTA, Ma Antónia C.; SEGURA, Luísa; MENDES, Amália (orgs.). Gramática do Português. Lisboa: Fundação Calouste Gulbenkian, 2013.

MATOS, Gabriela. Estrutura-P, Transformações, Predicados Elípticos e Pronominais. Actas do $I X$ Encontro da Associação Portuguesa de Linguística. Lisboa: APL/Edições Colibri, 1994, p. 305319. 
. Estruturas binárias e monocêntricas em sintaxe: algumas observações sobre a coordenação de projecções máximas. Actas do X Encontro Nacional da Associação Portuguesa de Linguística. Lisboa: APL, 1995, p. 301-315.

. Configurações Sintácticas em Estruturas de Colocação Simultânea de Clítico. In: BRITO, Ana Maria; OLIVEIRA, Fátima; LIMA, Isabel Pires de; MARTELO, Rosa Maria (orgs.). Sentido que a Vida Faz - Homenagem a Óscar Lopes, 705-717. Porto: Campo das Letras, 1997. ISBN 972-610-047-X.

. Across-the-board clitic placement in Romance languages. Probus 12, p. 229-259, 2000.

. Estruturas de coordenação. In: MATEUS, M. H., et alii. Gramática da Língua Portuguesa. Lisboa: Caminho, 2003, p. 549-592.

. Parataxe como coordenação e justaposição - evidência a partir de um caso de elipse. Actas do XX Encontro Nacional da Associação Portuguesa de Linguística, Lisboa: APL, 2005, p. 687699.

. Coordenação, Subordinação e adjunção. Lição apresentada para Provas de Agregação. Lisboa: Faculdade de Letras, Universidade de Lisboa, 2006.

.Appositive sentences and the structure(s) of coordination. In: TORK, Daniéle; WETZELS, Leo (eds.). Romance Languages and Linguistic Theory 2006. Amsterdam; Philadelphia: John Benjamins Publishing Company, 2009, p. 159-174.

MATOS, Gabriela; RAPOSO, Eduardo. Estruturas de coordenação. In RAPOSO, Eduardo B. P.; NASCIMENTO, M ${ }^{a}$ Fernanda B.; MOTA, Ma Antónia C.; SEGURA, Luísa; MENDES, Amália (orgs.). Gramática do Português, vol. II, cap. 35. Lisboa: Fundação Calouste Gulbenkian, 2013, p. 1761-1817.

MATOS, Gabriela; COLAÇO, Madalena. Ênclise e Próclise na coordenação. Linguística, Revista de Estudos Linguísticos da Universidade do Porto, vol. 9, 2014.

MCDANIEL, D.; CAIRNS, H.S. The child as informant: Eliciting linguistic judgments from 
young children. Journal of Psycholinguistic Research, v. 19, n. 5, p. 331-344, 1990a.

MCDANIEL, D.; CAIRNS, H.S. The processing and acquisition of control structures by young children. In: FRAZIER, L.; VILLIERS, J. de (eds.). Language Processing and Language Acquisition. Dordrecht: Kluwer, 1990 b.

MUNN, Alan Boag. Topics in the Syntax and Semantics of Coordinate Structures. Dissertação de Doutoramento, Universidade de Maryland, 1993.

NUNES, Jairo. The Copy Theory of Movement and Linearization of Chains in the Minimalist Program. Dissertação de Doutoramento, Universidade de Maryland, 1995.

. Linearization of Chains and Sideward Movement. Linguistic Inquiry Monograph 43. Cambridge, MA: MIT Press, 2004.

QUIRK, Randolph; GREENBAUM, Sidney. LEECH; Geoffrey; SVARTVIK, Jan. A Comprehensive Grammar of the English Language. London / New York: Longman, 1985.

ROSS, John R. Constraints on Variables in Syntax. Cambridge MA: MIT Press, 1967.

VALMALA, Vidal. On the position of central adverbial clauses. Anuario del Seminario de Filología Vasca “Julio de Urquijo”, XLIII, p. 951-970, 2009.

WILLIAMS, Edwin. A reinterpretation of evidence for verb movement in French. In: LIGHTFOOT, D.; HORNSTEIN, N. (eds.). Verb Movement. Cambridge: Cambridge University Press, 1994a, p. 189-205.

. Thematic Structures in Syntax. Cambridge MA: The MIT Press, 1994b. 